\title{
Understanding Consumers' Attitudes Toward Fruits and Vegetable Attributes: A Multi-Method Approach
}

\author{
Terrence Thomas ${ }^{1, *}$, Cihat Gunden², and Bulent Miran ${ }^{2}$ \\ ${ }^{1}$ Department of Agribusiness, Applied Economics and Agriscience Education, North Carolina Agricultural and \\ Technical State University, 1601 E Market St, Greensboro, NC 27411, USA \\ ${ }^{2}$ Department of Agricultural Economics, Faculty of Agriculture, Ege University, Bornova, Izmir 35100, Turkey
}

\begin{abstract}
Background: Results from previous work indicated that when consumers make purchasing decisions, they pay more attention to freshness, taste and hygiene attributes of fruits and vegetables than price and nutritional value, when these attributes are considered individually.

Methods: To shed light on the underlying factors that shape the pattern of reported preferences, researchers used five doubly censored Tobit models to analyze data generated from a fuzzy pairwise comparison model (FPC) to explain the pattern of reported preferences. In the model, nutritive value, hygiene, taste, price and freshness were separately regressed on a number of demographic and personal characteristics variables. For this study, a random sample was drawn proportionate to population size by county in Georgia, North Carolina and South Carolina. Data were collected from 412 respondents.

Results: Higher levels of education and income did not affect how consumers rate the nutritional value of fruits and vegetables. This relative lack of difference among consumers as classified in the model, along with results that showed consumers giving a higher preference rating to hygiene, taste and price offer support for the notion that the nutritional value attribute plays a subsidiary role in consumers purchasing decisions.

Conclusion: The multi-method approach used in this study provides information on the demographic characteristics of consumers that influence attitudes and behaviors toward fruit and vegetable attributes. Nutrition educators and marketers will be able to use this knowledge about consumers' attitudes and behaviors to customize programs that more accurately address consumers' preferences.
\end{abstract}

Keywords: Consumer Preferences, Purchasing Behavior, Fruits and Vegetables, Tobit, Fuzzy Pairwise Comparison.

\section{INTRODUCTION}

Success in realizing increased dietary intake of fruit and vegetables will depend in part on knowledge of consumer preferences for the attributes of fruits and vegetables and the underlying factors that shape consumer preferences. Recognizing that consumers differ in their preferences for the attributes of fruits and vegetables, and that consumers take into account more than one attribute of fruits and vegetables in making their purchase decisions, and also realizing that personal and other demographic features of consumers impact choice and behavior, the aim of the study is to employ a multi-method approach to add scope and depth to our understanding of consumers' attitude and behavior toward fruits and vegetable attributes. An attitude is a stable overall evaluation that expresses how much we like or dislike an action, person or object. A consumer's overall evaluation of a product (attitude) can be traced to the interaction among three basic

*Address correspondence to this author at the Department of Agribusiness, Applied Economics and Agriscience Education, North Carolina Agricultural and Technical State University, 1601 E Market St, Greensboro, NC 27411, USA; Tel: (336) 285-4733; Fax: (336) 334-7658; E-mail: twthomas@ncat.edu dimensions of an attitude: beliefs, feelings and behavioral intentions [1]. A consumer's belief regarding a product elicits feelings-favorable or unfavorableabout a product; the consumer's feelings, in turn, motivate the consumer to engage in behavior with respect to the particular product (behavioral intention). Thus, a consumer's attitude toward a product is based on their overall evaluation of the particular product constructed from the set of features or associations linked to that product [2]. Consequently, a consumer's attitude expresses how much that consumer likes or dislikes a product and their tendency to engage in a particular behavior toward that product. In summary, attitudes are important because attitudes explain why consumers have a particular preference for the attributes of a particular fruit or vegetable and why consumers act to purchase fruits or vegetables with their preferred attribute. So then, efforts to discern factors that shape consumers attitudes toward fruits and vegetable attributes have implications for marketing and for encouraging increased consumption of fruits and vegetables. In this study, consumers' preference is conceived as consumers' overall evaluation of fruit and vegetable attribute following the attitude model described in this paragraph. 


\section{REVIEW OF LITERATURE}

Research on consumer attitudes toward food products' attributes have been extensively investigated using different methodological approaches. For example, Voon, Ngui and Agrawal [3] used Structural Equation Modeling (SEM) to identify the determinants of willingness to purchase organic food among consumers. The authors hypothesized that health and environmental concerns, trust on organic food claims, perception of organic food attributes, subjective norms and high affordability positively impacted the attitudes towards organic food. Chen [4] employed Food Choice Questionnaire (FCQ) to collect data on consumers' attitude toward genetically modified (GM) foods and used ordinary least square method to estimate the effect of food choice motives on consumers' attitudes toward GM foods. The findings indicated that mood, sensory appeal, price and familiarity contributed positively to consumers' attitudes toward GM foods. The Theory of Reasoned Action (TRA) developed by Ajzen and Fishbein [5] and the Theory of Planned Behavior (TPB) purposed by Ajzen [6] as an extension of the TRA, have been applied along with a wide range of statistical and econometrics methods to identify consumers' beliefs and behavioral intensions in explaining consumers' behaviors. For instance, Gotschi et al. [7] applied the TRA and Discriminant Analysis to explore the role of knowledge, cultural patterns, sociodemographic characteristics, subjective norms and attitudes toward organic products and self-reported shopping behavior. The results showed that knowledge of organic products was not significant, whereas cultural differences proved more useful in predicting attitudes toward and shopping behaviors for organic products. Chen [8] established an integrated research framework based on Attitude Model and the TPB using SEM to analyze consumers' beliefs and purchase intentions toward GM foods. In the Attitude Model, consumers' overall attitude toward GM foods was only affected by perceived benefits from GM foods which were determined by beliefs about technology and nature, food neophobia, alienation from the marketplace and perceived knowledge of gene technology. In another study on the application of TPB, Vermeir and Verbeke [9] explored the influence of determinants postulated by TPB and the role of individual characteristics such as confidence and values in explaining consumers' intention to purchase sustainable dairy products by using stepwise multiple regression models. The results showed that consumers' perceived social influences, perceived effectiveness and perceived availability had significant positive effects on behavioral intention ${ }^{1}$ towards purchasing sustainable dairy products.

In addition to beliefs and behavioral intentions, studies on consumers' preferences for food product attributes have been conducted to determine the most preferable attributes and identify the critical factors affecting consumers' preferences. Here preferences refer to consumers' expressed like or dislike for a product based on an overall evaluation or overall attitude toward the product. For example, Gao et al. [10] determined consumers' preferences for fresh fruit attributes - freshness, flavor, appearance, juiciness, fruit size, price, ease of peeling and seeds. The authors estimated eight Ordered Probit Models, one for each attribute; the dependent variables were the respondents' ordinal rating of their level of preference for each attribute and the independent variables were consumers' characteristics and behavioral variables. The findings revealed that freshness, flavor and appearance were the most important attributes. The results of the models revealed that location and marital status were the most important demographic variables explaining the heterogeneous preferences among consumers. Moser et al. [11] summarized existing research related to consumer preferences for fresh fruit and vegetable attributes. The authors identified specific attributes that influenced consumer buying behavior and willingness to pay for integrated pest management (IPM), organically grown and other sustainably produced fresh fruit and vegetables. These attributes were listed as visual, smell and taste, quality, credence attributes, price, brand and packaging. The study reported that health-related attributes were the most significant reasons to buy sustainable food in the literature reviewed.

Several other studies have also investigated how consumers' attitude toward fruit and vegetable attributes influence their willingness to purchase and to pay for fruit and vegetables. For example: Ernst et al. [12] examined visual, smell and taste attributes; Onozaka et al. [13] and Boccaletti and Nardella [14] investigated health and associated attributes; Morteza

\footnotetext{
${ }^{1}$ At the beginning of this review, attitude was conceptualized as having three components: beliefs, feelings and intentions to behave. In the studies reviewed above, authors tend to employ a micro level of analysis using beliefs and or feelings to represent overall attitude and using behavioral intentions and or willingness to pay as a separate outcome variables rather than as integral component of overall attitude.
} 
et al. [15] studied environmental attributes; Darby et al. [16]; Thilmany et al. [17] and Rodriguez-lbeas [18] examined the attributes of origin, local and farmers' support and Caputo et al. [19] investigated labels and certification attributes.

In this study, fuzzy pairwise comparison was used to derive preference ratings for attributes, which results in capturing consumers' preference ratings in richer detail for the following reasons: 1) The FPC is similar to traditional pair-wise comparisons. Consumers are asked to compare the attributes one pair at a time. However, unlike the traditional pair-wise method, consumers are not forced to make a binary choice between two attributes. Consumers are permitted to indicate the degree of preference for one attribute over another, and response indicating indifference between attributes is permitted. 2) Unlike the other methods, the scale values are based on the consumers' entire set of paired comparisons. 3) FPC more accurately represents the natural range of response patterns that are possible. These preference ratings were then regressed on consumers' demographic characteristics using Tobit technique. This multi-method approach is in contrast to the studies reviewed which used a single method and non-comparative itemized rating scales. Fuzzy pairwise comparison and Tobit analysis will provide suppliers of fruits and vegetables, health professionals and policy makers with the insight they need to customize their products and services to meet the needs of specific groups of consumers instead of producing a generic, one-size-fits-all product or service.

\section{MATERIALS AND METHOD}

The sample for this study was designed following the protocol described by Dillman et al. [20]. The sample was drawn randomly and proportionate to population size by county in Georgia, North Carolina and South Carolina. Based on the sampling frame parameters identified using the referenced protocol, the required sample was purchased from Survey Sampling Inc. Researchers designed and formatted a Fuzzy Pairwise Comparison (FPC) questionnaire to be compatible with the data collection protocol of Survey Monkey, and trained enumerators to use the questionnaire to collect the data. Enumerators asked consumers to make pairwise comparisons of five food attributes: nutritional value, hygiene, taste, affordable price and freshness to determine their preference for one attribute over the other. The response rate for this survey was calculated to be $39 \%$ applying American Association of Public Opinion Researchers (AAPOR) standard for response rate 2 (RR2) (AAPOR, 2008). After removing incomplete questionnaires, data from 412 respondents were used in the analysis.

The data collected was analyzed in a previous study that employed fuzzy pairwise comparison (FPC) to profile consumer preferences [21]. The Fuzzy matrix $R$ can be represented as follows [22]:

$R_{i j}=\left\{\begin{array}{l}0 \quad \text { if } i=j \forall i, j=1, \ldots, n \\ r_{i j} \text { if } i \neq j \forall i, j=1, \ldots, n\end{array}\right.$

In the FPC method, a measure of preference, $\mu$ can be calculated for each attribute by using the consumer's preference matrix $R$. The intensity of each preference is measured separately using the following equation:

$\mu_{j}=1-\left(\sum_{i=1}^{n} R_{i j}^{2} /(n-1)\right)^{1 / 2}$

$\mu \mathrm{j}$ has a range in the closed interval $[0,1]$. A larger value of $\mu \mathrm{j}$ indicates greater intensity of preference for attribute j. In identifying consumer preferences, researchers ranked the importance of the attributes following Gao et al. [10]. In the current study, preference measures derived from a FPC model were separately regressed on demographic variables using five censored Tobit models as a means of identifying the underlying factors that drive the expression of respondents' preferences.

The Tobit model is specified as follows:

$$
\begin{array}{ll}
Y_{i j}=\beta_{0}+\sum_{i=1}^{N} \beta_{i} X_{i}+u_{i} & \text { if } u_{i}>-\beta_{0}-\sum_{i=1}^{N} \beta_{i} X_{i} \\
Y_{i j}=0 & \text { if } u_{i} \leq-\beta_{0}-\sum_{i=1}^{N} \beta_{i} X_{i}
\end{array}
$$

where Yij; is the measure of preference for attributes (nutrition value, hygiene, taste, price and freshness), i; Xi's are explanatory variables that influence preference of the attributes, $\mathrm{N}$ is the number of explanatory variables, $\beta$ and $u$ are parameters of the model and random error term respectively. Since the consumer preference measures are censored between zero and one, the doubly censored Tobit model is chosen in this study [23-24]. 


\section{RESULTS AND DISCUSSION}

Descriptive statistics for consumers' pair-wise comparisons of the attributes of fruit and vegetables obtained from the FPC model are presented in Table 1. The fruit and vegetable attributes are ranked from most to least preferable using the reported degree of the consumer preferences. The results show that the fruit and vegetable attribute most preferred by consumers is freshness with a preference rating of 0.579. Gao et al. [10] reported a similar pattern of preference in their study on consumers' preferences for fresh citrus. Consumers prefer the other food attributes in the following order: Taste (0.452), hygiene (0.449), nutritional value (0.428) and affordable price (0.411). In this sample, consumers seem to value freshness, taste and hygiene over price and nutritional value. The Friedman test was used to see if there was a difference in the rankings of the fruit and vegetable attributes. The Friedman test, which is significant $\left(\chi^{2}=177.71\right.$; $p<0.01)$, confirms that some attributes are preferable to the others. Kendall's W test was used to measure the degree of agreement among consumers. The value of Kendall's $W$ is 0.11 , which indicates that the level of agreement among consumers in ranking the attributes is very low. A low level of agreement among consumers is an indication of the heterogeneity of consumers' preferences for the attributes of fruits and

Table 1: Descriptive Statistics of Consumer Preferences Towards Fruits and Vegetable Attributes

\begin{tabular}{|c|c|c|c|c|}
\hline Attributes & Mean & Standard deviation & Minimum & Maximum \\
\hline \hline Nutrition Value & 0.428 & 0.122 & 0.024 & 0.929 \\
\hline Hygiene & 0.449 & 0.142 & 0.049 & 0.049 \\
\hline Taste & 0.452 & 0.128 & 0.000 & 0.868 \\
\hline Affordable Price & 0.411 & 0.154 & 0.150 & 1.000 \\
\hline Freshness & 0.579 & 0.159 & & \\
\hline
\end{tabular}

Table 2: Variable Description for Tobit Models

\begin{tabular}{|c|c|c|c|c|}
\hline Variable & Type & Description & Mean & $\begin{array}{c}\text { Std } \\
\text { Deviation }\end{array}$ \\
\hline GENDER & Dummy & Sex of respondent> 1: Male, 0: Female & 0.306 & 0.46 \\
\hline AGE & Continuous & Age in years & 54.153 & 15.81 \\
\hline EDUCATION & Dummy & Education > 1: BS and up, 0: Less than $B S$ & 0.577 & 0.49 \\
\hline MARITAL STATUS-MARRIED & Dummy & Marital status $>1$ : Married, $0:$ Single & 0.035 & 0.18 \\
\hline MARITAL STATUS-SEPARATED & Dummy & Marital status $>1$ : Separated, 0 : Single & 0.069 & 0.25 \\
\hline MARITAL STATUS-DIVORCED & Dummy & Marital status $>1$ : Divorced, 0 : Single & 0.099 & 0.30 \\
\hline MARITAL STATUS-WIDOWED & Dummy & Marital status $>1$ : Widowed, 0 : Single & 0.692 & 0.46 \\
\hline RACE-WHITE & Dummy & Race $>1$ : White, 0: African American & 0.005 & 0.07 \\
\hline RACE-ASIAN & Dummy & Race $>1$ : Asian, 0: African American & 0.012 & 0.11 \\
\hline RACE-NATIVE AMERICAN & Dummy & Race $>1$ : Native American, 0 : African American & 0.012 & 0.11 \\
\hline RACE-HISPANIC & Dummy & Race $>1$ : Hispanic, 0: African American & 0.017 & 0.13 \\
\hline RACE-OTHER & Dummy & Race $>1$ : Other, 0 : African American & 0.095 & 0.29 \\
\hline EMPLOYEMENT-PARTTIME & Dummy & Employment $>1$ : Part time, 0 : Unemployed & 0.473 & 0.50 \\
\hline EMPLOYEMENT-FULLTIME & Dummy & Employment $>1$ : Full time, 0 : Unemployed & 0.282 & 0.45 \\
\hline SALARY-MIDLEVEL & Dummy & Annual salary> 1: $\$ 30000-50000$, 0: less than $\$ 30000$ & 0.165 & 0.37 \\
\hline SALARY-UPPERLEVEL & Dummy & Annual salary> 1: Greater than $\$ 50000$, 0: less than $\$ 30000$ & 0.306 & 0.46 \\
\hline
\end{tabular}


Table 3: The Results of Five Tobit Models

\begin{tabular}{|c|c|c|c|c|c|}
\hline & $\begin{array}{c}\text { Model 1: } \\
\text { Nutrition Value }\end{array}$ & $\begin{array}{l}\text { Model 2: } \\
\text { Hygiene }\end{array}$ & $\begin{array}{l}\text { Model 3: } \\
\text { Taste }\end{array}$ & $\begin{array}{c}\text { Model 4: } \\
\text { Price }\end{array}$ & $\begin{array}{l}\text { Model 5: } \\
\text { Freshness }\end{array}$ \\
\hline Variable & $\begin{array}{l}\text { Coefficient } \\
\text { (Std. Error) }\end{array}$ & $\begin{array}{l}\text { Coefficient } \\
\text { (Std. Error) }\end{array}$ & $\begin{array}{l}\text { Coefficient } \\
\text { (Std. Error) }\end{array}$ & $\begin{array}{l}\text { Coefficient } \\
\text { (Std. Error) }\end{array}$ & $\begin{array}{l}\text { Coefficient } \\
\text { (Std. Error) }\end{array}$ \\
\hline Constant & $\begin{array}{c}0.46501^{* * *} \\
(0.02944)\end{array}$ & $\begin{array}{c}0.48461^{* * *} \\
(0.03457)\end{array}$ & $\begin{array}{c}0.44676^{\star * *} \\
(0.03047)\end{array}$ & $\begin{array}{l}.46601^{* * *} \\
(0.03636)\end{array}$ & $\begin{array}{c}0.49429^{* * *} \\
(0.04070)\end{array}$ \\
\hline GENDER & $\begin{array}{l}-0.00922 \\
(0.01305)\end{array}$ & $\begin{array}{l}-.02782^{*} \\
(0.01532)\end{array}$ & $\begin{array}{c}0.01696 \\
(0.01350)\end{array}$ & $\begin{array}{c}-0.03528^{* *} \\
(0.01612)\end{array}$ & $\begin{array}{c}0.01786 \\
(0.01806)\end{array}$ \\
\hline AGE & $\begin{array}{l}-0.00060 \\
(0.00048)\end{array}$ & $\begin{array}{l}-0.00038 \\
(0.00056)\end{array}$ & $\begin{array}{l}0.000177 \\
(0.00049)\end{array}$ & $\begin{array}{l}0000587 \\
(0.00059)\end{array}$ & $\begin{array}{c}0.00099 \\
(0.00066)\end{array}$ \\
\hline EDUCATION & $\begin{array}{c}0.00678 \\
(0.01499)\end{array}$ & $\begin{array}{l}-0.00935 \\
(0.01761)\end{array}$ & $\begin{array}{c}0.01084 \\
(0.01552)\end{array}$ & $\begin{array}{c}-0.04552^{* *} \\
(0.01854)\end{array}$ & $\begin{array}{c}0.00586 \\
(0.02074)\end{array}$ \\
\hline MARITAL STATUS_MARRIED & $\begin{array}{c}0.01614 \\
(0.01104)\end{array}$ & $\begin{array}{c}0.00188 \\
(0.01296)\end{array}$ & $\begin{array}{l}-0.00649 \\
(0.01143)\end{array}$ & $\begin{array}{l}-0.01611 \\
(0.01363)\end{array}$ & $\begin{array}{c}0.00284 \\
(0.01529)\end{array}$ \\
\hline MARITAL STATUS_SEPARATED & $\begin{array}{c}-0.05591^{* *} \\
(0.02522)\end{array}$ & $\begin{array}{c}0.00513 \\
(0.02961)\end{array}$ & $\begin{array}{l}-0.02799 \\
(0.02610)\end{array}$ & $\begin{array}{l}-0.02256 \\
(0.03112)\end{array}$ & $\begin{array}{c}.06173^{*} \\
(0.03499)\end{array}$ \\
\hline MARITAL STATUS_DIVORCED & $\begin{array}{c}0.02460 \\
(0.01956)\end{array}$ & $\begin{array}{c}0.01931 \\
(0.02296)\end{array}$ & $\begin{array}{c}0.02029 \\
(0.02024)\end{array}$ & $\begin{array}{c}0.03044 \\
(0.02413)\end{array}$ & $\begin{array}{l}-0.04251 \\
(0.02700)\end{array}$ \\
\hline MARITAL STATUS_WIDOWED & $\begin{array}{c}0.01523 \\
(0.01907)\end{array}$ & $\begin{array}{l}-0.02634 \\
(0.02239)\end{array}$ & $\begin{array}{c}0.01420 \\
(0.01974)\end{array}$ & $\begin{array}{c}0.00833 \\
(0.02353)\end{array}$ & $\begin{array}{l}-0.02215 \\
(0.02634)\end{array}$ \\
\hline RACE_WHITE & $\begin{array}{c}0.01231 \\
(0.01326)\end{array}$ & $\begin{array}{c}0.01605 \\
(0.01558)\end{array}$ & $\begin{array}{c}0.01400 \\
(0.01373)\end{array}$ & $\begin{array}{l}-0.01252 \\
(0.01638)\end{array}$ & $\begin{array}{l}-0.01848 \\
(0.01834)\end{array}$ \\
\hline RACE_ASIAN & $\begin{array}{c}0.08198 \\
(0.06319)\end{array}$ & $\begin{array}{c}0.02412 \\
(0.07421)\end{array}$ & $\begin{array}{c}0.02013 \\
(0.06542)\end{array}$ & $\begin{array}{l}-0.02335 \\
(0.07798)\end{array}$ & $\begin{array}{c}0.04363 \\
(0.08723)\end{array}$ \\
\hline RACE_NATIVE AMERICAN & $\begin{array}{l}-0.02689 \\
(0.04852)\end{array}$ & $\begin{array}{l}-0.01906 \\
(0.05698)\end{array}$ & $\begin{array}{c}0.06466 \\
(0.05023)\end{array}$ & $\begin{array}{c}0.01549 \\
(0.05988)\end{array}$ & $\begin{array}{l}-0.00979 \\
(0.06691)\end{array}$ \\
\hline RACE_HISPANIC & $\begin{array}{l}-0.05598 \\
(0.04857)\end{array}$ & $\begin{array}{l}-0.03942 \\
(0.05703)\end{array}$ & $\begin{array}{c}0.02750 \\
(0.05028)\end{array}$ & $\begin{array}{l}0.12490^{* *} \\
(0.05993)\end{array}$ & $\begin{array}{l}-0.08600 \\
(0.06696)\end{array}$ \\
\hline RACE_OTHER & $\begin{array}{l}-0.01140 \\
(0.04241)\end{array}$ & $\begin{array}{c}0.01824 \\
(0.04980)\end{array}$ & $\begin{array}{c}-0.12626^{\star * *} \\
(0.04390)\end{array}$ & $\begin{array}{c}-0.10437^{\star *} \\
(0.05233)\end{array}$ & $\begin{array}{c}0.07052 \\
(0.05892)\end{array}$ \\
\hline EMPLOYEMENT_PARTTIME & $\begin{array}{l}-0.01165 \\
(0.02181)\end{array}$ & $\begin{array}{l}-0.02186 \\
(0.02562)\end{array}$ & $\begin{array}{l}-0.00291 \\
(0.02258)\end{array}$ & $\begin{array}{c}0.02114 \\
(0.02692)\end{array}$ & $\begin{array}{c}0.03638 \\
(0.03015)\end{array}$ \\
\hline EMPLOYEMENT_FULLTIME & $\begin{array}{l}-.03717^{* *} \\
(0.01634)\end{array}$ & $\begin{array}{l}-0.03110 \\
(0.01919)\end{array}$ & $\begin{array}{l}-0.02214 \\
(0.01692)\end{array}$ & $\begin{array}{l}-0.02103 \\
(0.02019)\end{array}$ & $\begin{array}{l}.07062^{\star * *} \\
(0.02262)\end{array}$ \\
\hline SALARY_MIDLEVEL & $\begin{array}{l}-0.00918 \\
(0.01562)\end{array}$ & $\begin{array}{l}-0.01738 \\
(0.01835)\end{array}$ & $\begin{array}{c}0.02370 \\
(0.01617)\end{array}$ & $\begin{array}{l}-0.00583 \\
(0.01929)\end{array}$ & $\begin{array}{l}-0.00110 \\
(0.02160)\end{array}$ \\
\hline SALARY_UPPERLEVEL & $\begin{array}{c}0.00245 \\
(0.02000)\end{array}$ & $\begin{array}{c}0.03548 \\
(0.02348)\end{array}$ & $\begin{array}{l}-0.03564^{*} \\
(0.02070)\end{array}$ & $\begin{array}{l}-0.04724^{*} \\
(0.02472)\end{array}$ & $\begin{array}{c}0.01878 \\
(0.02768)\end{array}$ \\
\hline Sigma & $\begin{array}{c}0.11912^{* * *} \\
(0.00415)\end{array}$ & $\begin{array}{c}0.13988^{* * *} \\
(0.00488)\end{array}$ & $\begin{array}{c}0.12332^{\star * *} \\
(0.00430)\end{array}$ & $\begin{array}{c}0.14699^{* * *} \\
(0.00522)\end{array}$ & $\begin{array}{c}0.16420^{* * *} \\
(0.00612)\end{array}$ \\
\hline
\end{tabular}

*** Significant at $p<0.01 ;{ }^{* *}$ Significant at $p<0.05 ;{ }^{*}$ Significant at $p<0.10$.

vegetables. This indicates that cluster analysis may be appropriate for a future investigation.

Table 2 shows basic descriptive statistics of the variables used for the five Tobit models to determine the underlying factors that influence consumers' preferences for fruit and vegetable attitudes.

Table 3 shows the results of five Tobit models. For each categorical variable the models used a reference 
variable for comparison. For example, single is a reference variable for marital status, which means the other categories of marital status are compared to single. Following this convention, African American is the reference variable for race, unemployed category is the reference for employment status, and low income level is the reference category for income.

Model 1 (Nutritional value): Apart from single consumers and the unemployed, there is no difference between the other consumers, as classified in the model. Contrary to what is expected, higher levels of education and income do not affect the level of importance consumers accord to the nutritional value of fruits and vegetables. Nutritional value may be playing a subsidiary role in consumers' purchasing decision regarding fruits and vegetables, since consumers indicate a higher level of preference for hygiene, taste and freshness.

Model 2 (Hygiene): As may be expected, females care more about the hygiene of foods than do males. Neither the race nor education level of consumers change the level of preference assigned to the hygiene of fruits and vegetables. Generally speaking, all consumers are concerned with the hygienic features of fruits and vegetables given the preference scores reported above, which is consistent with the assumption of that hygiene is the default attribute of fruits and vegetables.

Model 3 (Taste): An interesting finding is that high income consumers are less interested in the taste of fruits and vegetables. This may mean that high income consumers' perception of taste is different from other consumers or the taste of high priced fruits and vegetables produced primarily for high income consumers is different from the commonly grown low priced fruits and vegetables.

Model 4 (Price): Females are more sensitive to the price of fruits and vegetables than males. Consumers with higher levels of education, particularly the ones with BS degree, are less sensitive to price of fruits and vegetables. As expected, upper level income consumers are not concerned with fruit and vegetable prices.

Model 5 (Freshness): Differences in attitude to the attributes of fruits and vegetables are observed for consumers classified in terms of marital and employment status. All the other consumers, as classified in the model, accord equal significance to the freshness attribute of fruits and vegetables. Naturally nobody wants to buy food that is not fresh.

In summary, when consumers make purchasing decisions, they pay more attention to freshness, taste and hygiene attributes of fruits and vegetables than price and nutritional value, when these attributes are considered individually.

However, multidimensional scaling shows that consumers tend to associate taste and price in making purchasing decisions under conditions of reduced freshness, nutritional value and hygiene [21]. In this case, it may be that consumers use the attributes of price and taste to guide their purchasing decisions if hygiene, freshness and nutritional value of fruits and vegetables are in question. As Model one in the Tobit analysis indicates, there is no difference among consumers in their evaluation of the nutritional value except for those classified in terms of employment and marital status. This relative lack of difference among consumers in the evaluation of nutritional value along with results that show consumers giving a higher preference rating to hygiene, taste and price offer support for the notion that the nutritional value attribute plays a subsidiary role in consumers' purchasing decisions. Consumers rating of nutritional value may be related to the fact that consumers rely on reported information rather than on direct experience as in the case of taste, freshness and other attributes. The Tobit Model results also show that the education level of consumers makes little difference in consumers' evaluation of the attributes. This implies that there would be no need to segment consumers based on education level in designing programs to influence consumers' attitude toward fruit and vegetable attribute. In the context of massive advertisement of other food products and its impact on consumers' attitude and behavior toward food, educational efforts should target consumers' preferences as a point of leverage for encouraging consumers to increase their consumption of fruits and vegetables. For example, nutrition educators could design programs to teach consumers to make tastier meals from fruits and vegetables, educate consumers on the connection among the food attributes and the relevance of each attribute to healthy eating and a healthier lifestyle. Additionally, grocers should develop strategies to make offerings of fruits and vegetables reflect consumer preferences.

The relatively low response rate suggests that the data generated could be affected by non-response 
error. However, current thinking suggests that low response rates do not always affect the quality of the statistics generated from surveys. The impact of nonresponse error depends on how non-response affects key survey statistics [25]. In this study, we believe that non-response error is not a major threat to the quality of statistics since similar studies [26] found similar response patterns. As Groves et al. [26, pp. 210] observed, "an important remaining challenge to survey researchers regarding non response is determining when it hurts the quality of survey statistics and when it does not. More research is needed on this issue. Without it there is no guarantee that efforts to increase response rates are wise. And without it, there is no way to just being satisfied with low response rates". Even with a relatively low response rate, this study still provides useful insights into consumers' evaluation of fruits and vegetables, but caution should be exercised in the application of findings.

\section{CONCLUSION}

In summary, these results present health educators and marketers with an opportunity to (1) employ knowledge of consumer preferences for fruits and vegetables to meet the needs of specific groups of consumers and (2) in developing a holistic education program, that teaches consumers to use information available on all the attributes: price, taste, hygiene and especially nutritional value in making purchasing decisions and in preparing tasty nutritious meals.

\section{ACKNOWLEDGEMENT}

This project was supported by the USDA National Institute of Food and Agriculture, Evans Allen project number \# NC.X-242-5-10-531-1.

\section{REFERENCES}

[1] McShane S, Von Glinow M. Organizational behavior. New York: Irwin McGraw Hill 2004.

[2] Hoyer WD, Maclnnis DJ. Consumer behavior. 5th ed. Ohio: South-Western Cengage Learning 2008.

[3] Voon JP, Ngui KS, Agrawal A. Determinants of willingness to purchase organic food: An exploratory study using structural equation modeling. International Food and Agribusiness Management Review 2011; 14: 103-20

[4] Chen MF. The gender gap in food choice motives as determinants of consumers' attitudes toward GM foods in Taiwan. British Food Journal 2011; 113: 697-709. http://dx.doi.org/10.1108/00070701111140052

[5] Ajzen I, Fishbein M. Understanding attitudes and predicting social behavior. New Jersey: Prentice-Hall 1980. http://dx.doi.org/10.1016/0749-5978(91)90020-T

[6] Ajzen I. The theory of planned behavior. Organizational Behavior and Human Decision Processes 1991; 50: 179-211.
Gotschi E, Vogel S, Lindenthal T, Larcher M. The role of knowledge, social norms, and attitudes toward organic products and shopping behavior: survey results from high school students in Vienna. The Journal of Environmental Education 2010; 41: 88-100. http://dx.doi.org/10.1080/00958960903295225

[8] Chen MF. An integrated research framework to understand consumer attitudes and purchase intentions toward genetically modified foods. British Food Journal 2008; 110: 559-79. http://dx.doi.org/10.1108/00070700810877889

[9] Vermeir I, Verbeke W. Sustainable food consumption among young adults in Belgium: Theory of planned behaviour and the role of confidence and values. Ecological Economics 2008; 64: 542-53.

http://dx.doi.org/10.1016/j.ecolecon.2007.03.007

[10] Gao Z, House LO, Gmitter FG, Valim MF, Plotto A, Baldwin, EA. Consumer preferences for fresh citrus: impacts of demographic and behavioral characteristics. International Food and Agribusiness Management Review 2011; 14: 2340.

[11] Moser R, Raffaelli R, Thilmany-McFadden D. Consumer preferences for fruit and vegetables with credence-based attributes: a review. International Food and Agribusiness Management Review 2011; 14: 121-42.

[12] Ernst S, Batte MT, Darby K, Worley T. 2006. What matters in consumer berry preferences: Price? source? quality? Journal of Distribution Research 2011; 37: 68-71.

[13] Onozaka $Y$, Bunch D, Larson D. What exactly are they paying for? Explaining the price premium for organic fresh produce. Agricultural and Resources Economics 2006; 9: 14.

[14] Boccaletti S, Nardella M. Consumer willingness to pay for pesticide-free fresh fruit and vegetables in Italy. International Food and Agribusiness Management Review 2000; 3: 297310.

http://dx.doi.org/10.1016/S1096-7508(01)00049-0

[15] Morteza H, Hobbs JE, McNamara L. Assessing consumer preferences for organically grown fresh fruit and vegetables in Eastern New Brunswick. International Food and Agribusiness Management Review 2009; 12: 81-100.

[16] Darby K, Batte MT, Ernst S, Roe B. Decomposing local: A conjoint analysis of locally produced foods. American Journal of Agricultural Economics 2008; 90: 476-86. http://dx.doi.org/10.1111/j.1467-8276.2007.01111.x

[17] Thilmany DD, Bond CA, Keeling Bond J. Going local: Exploring consumer behavior and motivations for direct food purchase. American Journal of Agricultural Economics 2008; 90: 1303-9.

http://dx.doi.org/10.1111/j.1467-8276.2008.01221.x

[18] Rodriguez-Ibeas R. Environmental product differentiation and environmental awareness. Environmental and Resources Economics 2007; 36: 237-54. http://dx.doi.org/10.1007/s10640-006-9026-y

[19] Caputo V, Nayga RM, Canavari M. Organic consumers' valuation for food miles labels.119th EAAE Seminar 2010: June 30-July 2; Capri, Italy.

[20] Dillman D, Smyth J, Christian L. Internet, mail, and mixed mode surveys: The total design method. 3rd ed. New Jersey: John Wiley \& Sons 2009.

[21] Gunden C, Thomas T. Assessing consumer attitudes towards fresh fruit and vegetable attributes. Journal of Food Agriculture \& Environment 2012; 10: 85-88.

[22] Van Kooten GC, Schoney RA, Hayward KA. An alternative approach to the evaluation of goal hierarchies among farmers. Western J Agric Econ 1986; 11: 40-49.

[23] Ramanathan R. Introductory econometrics with applications. Fort Worth: The Dryden Press 1997. 
[24] Greene W. Econometric analysis. 5th ed. New Jersey: Prentice Hall 2003.

[25] Groves RM, Fowler FJ, Couper MP, Lepkowski JM, Singer E, Tourangeau R. Survey Methodology. 2nd ed. New Jersey: Wiley 2009.
[26] Thomas T, Gunden C. Investigating consumer attitudes toward food produced via three production systems: Conventional, sustainable and organic. Journal of Food Agriculture \& Environment 2012; 10: 55-58.

Received on 29-08-2015

Accepted on 17-09-2015

Published on 28-10-2015

DOI: http://dx.doi.org/10.6000/1929-5634.2015.04.03.3

(C) 2015 Thomas et al.; Licensee Lifescience Global.

This is an open access article licensed under the terms of the Creative Commons Attribution Non-Commercial License (http://creativecommons.org/licenses/by-nc/3.0/) which permits unrestricted, non-commercial use, distribution and reproduction in any medium, provided the work is properly cited. 